\title{
Proximidad y participación ciudadana
}

\author{
Jorge Ceja Martínez \\ Universidad de Guadalajara, México.
}

\begin{abstract}
"Nosotros vemos que es fundamental hacer una combinación entre la democracia representativa, en que tú eliges a una persona para que te represente, con la democracia participativa, en que tú actúas en lo cotidiano, fiscalizando la acción de los representantes, reforzándolos cuando ellos lo necesiten y sustituyéndolos, inclusive, cuando ellos no sean afines con las necesidades o las políticas elaboradas solidarias $y$ colectivamente en la base... En un fenómeno urbano con millares de personas, tenemos que combinar la democracia indirecta, representativa con la democracia directa, participativa".

Olivio Dutra, ex alcalde de Porto Alegre, Brasil. ${ }^{1}$
\end{abstract}

En los últimos años ha crecido el interés por conocer el papel que dentro y desde su entorno inmediato desempeñan los actores locales en la reproducción o transformación de la vida social. Entre las causas que lo han propiciado se encuentra el desarrollo y proliferación de novedosas expresiones de la sociedad civil organizada, la aparición de nuevos actores individuales y colectivos, y la irrupción de las escalas local y regional, gracias a incipientes procesos de descentralización estatal y alternancia política. Actores y territorios cobran relevancia al demandar mayores niveles de autonomía política, económica y administrativa. A pesar de que los procesos de descentralización estatal y de alternancia 
política municipal pueden considerarse (tanto para el caso mexicano, en particular, como para el latinoamericano en general) como fenómenos aún en germen -y por lo tanto poco sólidos y generalizados-, han logrado atraer la atención de amplios sectores, entre quienes los académicos ocupan un lugar.

Sin embargo, esta preocupación por intentar dar cuenta de lo (y desde lo) micro y de su relación con el orden macrosocial; por reconocer la existencia de variados intereses entre actores locales y extralocales y del interjuego que éstos y sus estrategias desencadenan; como también por registrar la existencia de múltiples realidades locales y regionales portadoras de singularidades propias, no es novedosa: forma parte de una larga tradición teórica y empírica en el campo de las ciencias sociales.

Lo que sí es un hecho, gracias a los fenómenos y procesos en curso, es su revitalización. Cuestión que contrariamente no sucede con los enfoques teóricos de interpretación estructural, para los cuales, genéricamente hablando, los sujetos ordinarios y los espacios pequeños (localidades, entidades y hasta países "en vías de desarrollo") se comportan y desarrollan en correspondencia a fuerzas "externas" o macroestructurales y en función de las directrices marcadas por algunos actores centrales.

Para quienes comparten esta segunda perspectiva, las escalas menores (meso y micro) son contenedoras o depositarias y sus lugareños testigos o víctimas de un devenir histórico que los excluye como posibles actores. Suele desconocerse la posibilidad de la existencia de márgenes de autonomía con respecto a las condicionantes extralocales y, con ello, a los sujetos se les despoja del atributo de la agencia humana, es decir, del de su propia historicidad. Entendiendo por agencia la capacidad que tienen los actores individuales y colectivos de procesar la experiencia social y de idear maneras de enfrentarse a las situaciones de la vida (Long 1992).

En años recientes hemos presenciado el crecimiento de la participación ciudadana que - más allá del ejercicio de sufragio- ha buscado abrir espacios para incidir de forma más constante en los asuntos de orden público. El proceso de globalización en curso (al cual no habría que verlo sólo como el rostro rejuvenecido y fortalecido de la "tiranía macroestructural" o del capitalismo mundial), ha significado 
la aparición de diversos fenómenos, tales como la emergencia de nuevos actores y, en relación con éstos, la de los espacios o lugares cotidianos en los que ellos se desenvuelven.

La globalización que, entre otros aspectos, conlleva el reordenamiento y expansión de los flujos de poder, tanto verticales (desde arriba) como horizontales (desde abajo); el resquebrajamiento, no sin ciertas resistencias, de relaciones históricamente construidas de naturaleza política, religiosa, sexual, comercial, cultural, ideológica, informacional, laboral, ambiental y, entre otras, migratoria (en ocasiones largamente sostenidas por las élites y el Estado, o construidas por luchas reivindicatorias como las conquistas sindicales o la seguridad social universal); de igual manera, el paulatino incumplimiento del Estado como agente regulador de bienestar social, ha propiciado la irrupción de la escala local y de nuevos actores colectivos e individuales.

Junto con el debilitamiento del papel del Estado como intermediador entre el capital y el trabajo -o por su acentuada opción preferencial por el primero- se han relajado también algunas de las funciones que éste desempeñaba en materia de regulación política, económica y cultural. En parte, debido a la inserción que lo local podrá estar asumiendo en correspondencia con las líneas fuerza de naturaleza extralocal. Pero también debido al hecho de que los procesos de descentralización estatal, democratización y alternancia política suelen propiciar la aparición de nuevos actores; como además lo generan los efectos sociales de las políticas económicas de ajuste estructural, que han orillado a la movilización de algunos sectores de la población que se ha visto afectada por los mismos.

Obviamente se trata de procesos que no son uniformes ni a escala regional, nacional o mundial. En verdad, existen muchos lugares del planeta en los que bien se pudiera afirmar que el orden de cosas, en su sentido más amplio, no ha cambiado. Por lo regular, se trata de regiones o países escasamente vinculados a las redes informacionales, culturales, migratorias y económicas de naturaleza global y cuyos sistemas políticos tienden a ser más bien de carácter estamental. En algunas ocasiones se podrá tratar de comunidades geográficamente aisladas, en las que una o varias familias han detentado tradicionalmente el poder local (los caciques, para el caso mexicano); en otras, de comunidades de diversa escala que aspiran a aislarse culturalmente. Sociedades que, a 
pesar de su aparente ensimismamiento cultural o tiranía comunitaria como diría Touraine (1997), están lejos de ser unidades totalmente homogéneas, por lo que siempre podrán encontrarse expresiones de resistencia frente a un orden que tiende a beneficiar a unos por encima de otros.

$\mathrm{Y}$ aunque a escala mundial resulta complejo realizar un recuento que dé cuenta de las manifestaciones territoriales de la globalización y de los procesos local-globalmente imbricados que ésta conlleva, no podemos desconocer la tendencia a la revitalización de este tipo de relaciones y, con ello, del papel estratégico de lo local y de la acción de los actores individuales y colectivos que cotidianamente se desenvuelven en este ámbito.

El presente trabajo se propone: a) dar cuenta del papel estratégico de lo local en el orden global; b) resaltar la importancia de la proximidad como laboratorio privilegiado para la construcción de democracia desde abajo y de conquista de derechos ciudadanos; c) destacar la relevancia que conllevan los procesos de descentralización y de alternancia política municipal como facilitadores de participación ciudadana; d) puntualizar los principales instrumentos que existen para facilitar la participación; y e) ilustrar los alcances que diversas experiencias latinoamericanas han arrojado en materia de participación ciudadana.

\section{Lo local y su importancia estratégica}

Borja y Castells (1997:14) han señalado que la importancia estratégica de lo local, como centro de gestión de lo global, puede apreciarse en tres ámbitos principales: 1 . El de la productividad y competitividad económicas, 2. El de la integración sociocultural y 3. El de la representación y gestión políticas.

Con respecto al primer ámbito reconocen que son precisamente los gobiernos locales los que más eficazmente pueden contribuir a mejorar las condiciones de producción y de competición de las empresas de las que depende, en último término, el bienestar de la sociedad local.

Si bien es cierto que los gobiernos locales cuentan con distintos medios para atraer y fomentar el desarrollo económico, también resulta cierto que éstos rara vez se interesan por que los beneficios -más allá de los empleos creados y de los sueldos remunerados de quienes 
forman parte de las unidades económicas- se extiendan de tal manera que impacten los niveles de bienestar de las sociedades locales. La norma de las políticas de fomento económico de los gobiernos locales (como también de los otros niveles de gobierno), más bien, ha consistido en crearle ventajas comparativas a los inversionistas, pero a costa de una mayor explotación de la mano de obra y de los recursos naturales locales. Los compromisos de los empresarios se reducen al pago de salarios e impuestos. Tampoco han resultado escasas las ocasiones en que los propios gobernantes se aprovechan de sus cargos para impulsar negocios personales, ya sea a título individual o asociados a empresas de diversa naturaleza. Sin embargo, esta actitud que puede considerarse como generalizada en muchos gobiernos locales no niega la posibilidad de que mandatarios con vocación democrática y preocupación social puedan impulsar -en coordinación con los empresarios y los sectores sociales-, diversas iniciativas que permitan extender de mejor manera la riqueza que, gracias a la infraestructura y al empleo de recursos locales, se genera en el campo de la producción económica.

Con respecto a la integración sociocultural, que Borja y Castells reconocen como el segundo ámbito del papel estratégico de lo local como centro de gestión de lo global, los autores afirman que "en un mundo de globalización de la comunicación es esencial el mantenimiento de identidades culturales diferenciadas a fin de estimular el sentido de pertenencia cotidiana a una sociedad concreta" (1997:16).

En principio nos enfrentamos a dos problemas: el primero es el relativo al papel que usualmente han desempeñado los gobiernos locales en cuanto a la integración social de las comunidades a las que representan, el cual en muchas ocasiones es prácticamente nulo.

Amplios sectores de población viven la marginación social y cultural dentro de sus propias sociedades locales sin que, muchas veces, las autoridades municipales muestren mayor preocupación por ello. Es difícil hablar de integración social cuando las diferencias entre las clases sociales, como en el caso latinoamericano, resultan abismales y cuando los gobernantes, más que atenuarlas, contribuyen a reproducir. Tradicionalmente pocas acciones suelen impulsarse -más allá de las celebraciones patrias y patronales locales - para fomentar la cultura y reforzar el universo simbólico que forma parte de las diversas identidades colectivas locales. Aunado a ello, resulta dudoso considerar que la integración social pueda darse cuando las instituciones locales guber- 
namentales no estimulan $-\mathrm{y}$ muchas veces inhiben o reprimen- la participación social. La integración debe fomentar el conocimiento de los otros, del territorio y sus problemas, y el respeto de las distintas prácticas culturales que coexisten dentro de este ámbito. Sin ella no se desarrollará un auténtico sentido de pertenencia a la comunidad y al territorio en el que ésta se asienta.

El segundo problema tiene que ver con lo que varios estudiosos han reconocido como la pérdida de capacidad del Estado para fomentar la identidad nacional. Capacidad que muchas veces negó (y reprimió) la existencia de las identidades locales y regionales.

La globalización ha tendido a disminuir el papel del Estado como garante de una identidad única y nacionalista (independientemente del hecho de que sus divulgadores oficiales hayan manifestado poca consistencia al respecto). El debilitamiento de la soberanía nacional y del Estado-nación tiende, al mismo tiempo, al fortalecimiento de las instancias locales de poder (Castro Silva y Keinert 1996). Los gobiernos locales ciertamente pueden impulsar la integración social al interior de sus propias comunidades, ser instancias que faciliten una mayor difusión y conocimiento de las manifestaciones culturales locales y extralocales, servir como punto de enlace entre las mismas, pero también contribuir, como en efecto muchas veces sucede, a acentuar la marginación y la desintegración social, gracias al desarrollo de políticas de exclusión económica, política y social.

La representación y gestión política, que Borja y Castells señalan como el tercer ámbito de importancia estratégica de lo local como centro de gestión de lo global, es sin lugar a dudas fundamental: es en esta esfera donde permanentemente se dan las relaciones entre autoridades de gobierno y ciudadanos. Es en este ámbito en el que se reproducen las relaciones verticales entre gobernantes y gobernados o donde se transforman en relaciones horizontales, gracias al ingrediente de la participación ciudadana y a la instauración de formas de expresión de democracia directa. Del involucramiento de los ciudadanos en la esfera de lo público y de la búsqueda de consenso gracias al uso de procedimientos democráticos depende, en buena parte, la integración de la sociedad local, la creación de instrumentos que contribuyan al logro de un mayor bienestar social y el desarrollo sustentable. 


\section{Aqui y abora}

\section{El principio de proximidad y la relación gobernantes-gobernados}

El ámbito local, el más próximo - por ser el que desde su propio espacio, tiempo y circunstancia involucra a todo mundo- es un campo privilegiado de incidencia ciudadana $y$, por lo tanto, de construcción de democracia desde abajo. Reconocer a la ciudad como actor colectivo y a sus habitantes como posibles personajes colectivos o individuales, es recordar —como afirma Hiernaux (1995) - que son las sociedades locales las que, a través de sus múltiples y articuladas aportaciones, hacen historia.

Pensar que la transición democrática se da sólo a partir de la presencia de fenómenos de alternancia en el poder ejecutivo federal o de las entidades o departamentos, o de la recomposición partidaria de los órganos legislativos de carácter federal, significa suponer que los ámbitos locales, sus expresiones de gobierno y la relación entre autoridades locales y gobernados no tienen importancia. Es reproducir una visión lineal y vertical (centralista) en torno al cambio social democrático, al suscribirlo como una cuestión meramente formal y dependiente exclusivamente de los partidos políticos. Sin negar la importancia que para la transición democrática implica la alternancia política a escala federal, cabe reconocer, como lo ha señalado Acosta (1996:16), al reflexionar sobre el caso mexicano, que:

El proceso de transformación democrática del país parte del supuesto de la democratización de los municipios, ya que es en este ámbito en el que se da el primer punto de articulación entre la sociedad y el gobierno y es el espacio territorial que enmarca la vida cotidiana de quienes lo habitan, en el cual satisfacen sus necesidades básicas y dirimen sus conflictos a partir de relaciones sociales y de poder específicos.

Es en los municipios -y en sus unidades territoriales- donde más se presenta la posibilidad de construir espacios públicos que involucren a la sociedad local en acciones de participación, representación y negociación que den forma a una gestión municipal que tenga como parámetro el reconocimiento de derechos (Aguirre 1995). Como lo manifiesta Dolores González,

la autonomía de las entidades locales se basa en el principio de la máxima proximidad entre la gestión pública y los ciudadanos. La 
gestión pública local es la esfera de gobierno más cercana a la población y, por lo tanto, la que se encuentra en mejor posición para involucrarla en el proceso de toma de decisiones concernientes a sus condiciones de vida; puede también hacer uso de sus conocimientos y experiencias para fomentar su desarrollo, mediante la promoción de la participación social y los movimientos de la sociedad civil en sus estructuras institucionales y mecanismos decisionales en el ámbito comunitario y municipal (1998:30-31).

Son sus pobladores los que están directamente afectados por los efectos negativos de los procesos de desarrollo y, por lo tanto, quienes están en mejores condiciones para encontrar y proponer soluciones (Arocena:1995).

Esto no significa que los efectos negativos del desarrollo sobre las comunidades sólo se deban a causas o agentes externos: también los hay internos; o que toda propuesta y actitud que se genere desde los grupos usualmente denominados populares o de cualquier persona de la localidad, sea necesariamente positiva. Lo que permite es la participación colectiva en la identificación de los problemas y necesidades existentes, así como el que, a partir de la discusión y el debate democrático, se lleguen a acuerdos con algún grado de consenso. Como lo ha señalado Arocena (1995:13), ideologizar las relaciones sociales de base nos impide ver que "eso que se llama la base no está exento de cálculo, de egoísmo, de búsqueda de lucro”. En ese tenor, con respecto al ámbito de lo popular, Jorge Alonso (1995:76-77) ha advertido que éste

No es homogéneo, sobre todo si se consideran las prácticas y se vislumbran diversos proyectos. Hay que reconocer que existen segmentos muy amplios que se encuentran desorganizados y entre los cuales se manifiestan prácticas anómicas sobre todo en las grandes ciudades. Por otra parte estos segmentos suelen aceptar acríticamente las ideologías y prácticas dominantes centradas en paternalismo, clientelismo y subordinación. En esos segmentos populares el interés por los ideales y prácticas democráticas es reducido o nulo. Es más, ahí se propician expresiones de autoritarismo, intolerancia, sumisión, etc. (...) Si bien surgen impulsos democratizadores en el seno de lo popular también puede propiciar terreno para que se enraícen tendencias fundamentalistas y a veces hasta fascistas. Es susceptible de desarticulación atomística y aún particularista por una parte y de articulación autoritaria por la otra. 
De igual manera nos sucede cuando ideologizamos a los movimientos sociales, a los partidos políticos de izquierda o derecha y -aunque cada vez con menos frecuencia- a la vanguardia, como máxima expresión de un grupo dirigente "integrado por personalidades lúcidas y transparentes cuya misión histórica es la de conducir a los oprimidos por los senderos de la libertad".

El ámbito municipal es, por lo menos para la mayoría de los ciudadanos, el más cercano a su alcance (sino el único). El municipio es el punto de encuentro entre la sociedad civil y el Estado, es por eso que se convierte en un espacio estratégico para la promoción del ejercicio democrático de gobierno y del poder (Lombera 1996), como tradicionalmente lo ha sido para inhibir la participación y reproducir a lo largo y ancho del país una cultura política basada en la subordinación frente a los poderes locales y una actitud de conformismo ante la centralización (en sus distintos rangos municipal, estatal y federal).

Desde los municipios resulta viable consolidar la organización y fuerza de la sociedad "para garantizar la construcción de una nueva cultura donde la fuerza principal esté en la población con formas de acción directa en el diseño de las políticas públicas" (Acosta. 1996:27). Alicia Ziccardi expresa:

Es precisamente en el nivel local, en el ámbito cotidiano, donde se ejercen los derechos ciudadanos, donde la gestión de bienes y servicios urbanos implica una relación directa entre la burocracia local y los usuarios, donde se pone a prueba la democracia territorial, donde la participación social puede incidir en el diseño e implementación de las políticas públicas (1995:15).

Las experiencias habidas en América Latina, como en México, en materia de transición democrática, procesos de descentralización, alternancia política en los ámbitos federal, regional o estatal y municipal, desarrollo de la sociedad civil y construcción de ciudadanía (aunque ciertamente desiguales tanto dentro de los países como para la región en su conjunto), han empezado a ilustrar nuevos procesos en germinación; así como el hecho de cómo, a pesar del fenómeno de las alternancias políticas, permanecen viejas inercias que inhiben la participación ciudadana y la construcción de nuevas alternativas desde los espacios locales. 
En efecto, si bien resulta difícil pensar que la puesta en marcha de nuevas modalidades de participación de democracia directa pueda darse en municipios o entidades donde ni siquiera se ha roto el monopolio del poder que ejerce un solo partido (o a través de éste algunas familias), tampoco debemos suponer que la alternancia política por sí sola garantizará procesos de empoderamiento popular y de participación ciudadana.

El problema, por lo tanto, no sólo tiene que ver en cómo se construyen las condiciones y marcos institucionales para que los distintos partidos políticos puedan, en igualdad de condiciones, contender por el poder gubernamental, sino también en cómo, a su vez, un nuevo orden democrático representativo puede servir como cimiento institucional para la ampliación de los derechos ciudadanos.

\section{La descentralización como facilitador de la participación}

La descentralización la podemos entender como la distribución del centro a la periferia del poder gubernamental. Se trata de un proceso mediante el cual se intenta revertir, con menor o mayor intensidad, el centralismo y la acumulación de poder que a expensas de unos poseen otros. Podemos a su vez pensar en varios centros de poder gubernamental y de relaciones asimétricas entre los mismos, donde los federales (legislativo, judicial y ejecutivo) tienen primacía sobre los estatales y, éstos a su vez, sobre los municipales.

Victoria E. Rodríguez (1997) señala que todos los tipos de descentralización son sólo variaciones del mismo fenómeno: la dispersión de funciones y poder del centro a la periferia. Para ello distingue los siguientes tipos de descentralización: a) descentralización política, la cual materializada a su máxima expresión tienen que ver con democratización, participación ciudadana y gobierno representativo; b) descentralización espacial, ésta propone la búsqueda de patrones de desarrollo urbano equitativos entre los distintos asentamientos que conforman un territorio; c) descentralización administrativa, tiene que ver con la transferencia de funciones de planeación y de manejo de recursos; y d) descentralización de mercado y privatización, se orienta, al adelgazamiento de las funciones desempeñadas por el sector público en materia del otorgamiento de bienes y servicios, así como en facilitar los medios para que la iniciativa privada pueda desenvolverse con las menores restricciones legales (desregulación). 
A su vez, la autora distingue tres modalidades de descentralización: 1 . La desconcentración, que tiene que ver con la transferencia de funciones, poder y recursos hacia las entidades, pero donde los lineamientos normativos, de supervisión, control, presupuestación y coordinación general son marcados por el centro, en quien recae finalmente la autoridad; 2. La delegación mediante la cual el gobierno central transfiere determinadas atribuciones a organismos semiautónomos, finalmente controlados por el gobierno central; y 3. La devolución cuya acepción usual en inglés (devolution), más que devolver o regresar, significa garantizar plena autonomía, lo que en todo caso ilustra mejor lo que debería ser un sistema federal de gobierno. Se trata de un proceso a través del cual el gobierno central le transfiere a los estados y municipios ciertas atribuciones, pero en estricto apego al reconocimiento de su autonomía, "lo diferencia a un gobierno local con estatus independiente de una administración local” (Rodríguez 1997:12), (ver cuadro 1). Por lo tanto, aunque las tres modalidades de descentralización implican transferencia de funciones, sólo en la devolución éstas se otorgan a organismos o entidades totalmente autónomas del gobierno central. Es en esta última donde finalmente se podrá valorar la voluntad descentralizadora del gobierno central y que, para el caso mexicano en términos formales, queda plasmada en el artículo 115 constitucional, y para el jalisciense, en el Título Séptimo de la Constitución Política del Estado de Jalisco (gobierno municipal, facultades y obligaciones de los ayuntamientos y hacienda y patrimonio municipal). ${ }^{2}$

\section{Cuadro 1}

Descentralización estatal: tipos y modalidades

\begin{tabular}{|l|l|}
\hline \multicolumn{1}{|c|}{ Tipos } & \multicolumn{1}{|c|}{ Modalidades } \\
\hline 1. Descentralización política & 1. Desconcentración \\
2. Descentralización espacial & 2. Delegación \\
3. Descentralización administrativa & 3. Devolución \\
$\begin{array}{l}\text { 4. Descentralización de mercado } \\
\text { y privatización }\end{array}$ & \\
\hline
\end{tabular}

Fuente: elaboración propia con base en Rodríguez (1997)

Aunque la descentralización estatal, al igual que la alternancia política municipal, puede significar cierta liberalización del control de lo 
político y de las decisiones relativas a las formas en que se obtienen y emplean los recursos públicos, ésta no necesariamente deriva en una mayor participación ciudadana, ya que, tanto los procesos de descentralización como los de alternancia, pueden darse en ausencia del ingrediente de la participación y para beneficio de un reducido grupo de poder. Es decir, también a nivel local, pero en su correspondencia con los gobernados, pueden reproducirse relaciones de carácter centralista, como de hecho se dan cuando se observan prácticas presidencialistas y autoritarias por parte de los gobernantes locales.

Son los ciudadanos ordinarios los que finalmente se ven afectados por esta triple centralización: la implementada por el gobierno central en perjuicio de los entidades estatales y municipales, ${ }^{3}$ la instrumentada por los gobiernos estatales en detrimento de los municipios y sus pobladores, así como la que cotidianamente ponen en marcha los gobiernos municipales a espaldas de los gobernados; y en quienes - por lo menos formalmente- reside la soberanía.

Es difícil pensar que en municipios donde no se ha dado la alternancia se puedan estar gestando procesos de descentralización política que impliquen una mayor participación de los habitantes en la toma de decisiones; particularmente en aquellos municipios donde los ayuntamientos han funcionado como guardianes de los intereses de oligarquías locales o regionales $\mathrm{y}$, en consecuencia, combatido cualquier expresión que se les oponga.

Es cierto que en muchos municipios sin antecedentes de alternancia han surgido movimientos de carácter popular que han forzado a que los gobernantes locales, presionados ante diversas formas de protesta, tomen decisiones en aras de satisfacer algunas demandas. Es el caso, por ejemplo, de muchos municipios urbanos, donde habitantes de asentamientos irregulares han logrado, en ocasiones a través de largas luchas, obtener la atención y compromiso del gobierno para satisfacer diversas necesidades, como la introducción de servicios e instalación de infraestructura urbana (redes de agua potable y alcantarillado, vigilancia, electrificación y alumbrado público, transporte, escuelas, mercados, regularización de la tenencia de la tierra, etc.). Sin embargo, es deseable que la participación cuente con canales institucionales que la promuevan y faciliten de manera natural, sin que se tenga que transitar por movimientos de lucha frontal (o de cooptación partidista o clientelar), muchas veces reprimidos violentamente por autoridades poco propensas 
a los valores democráticos. Lo anterior no invalida el recurso de la protesta en sus distintas manifestaciones a la que muchos grupos sociales han tenido que acudir como el único medio a su alcance para lograr la satisfacción de sus necesidades; formas de organización que se han presentado debido a la inexistencia de canales institucionales de participación democrática y, sobre todo, por la insensibilidad de los gobernantes para atender las demandas populares.

En un régimen democrático, donde las instituciones de gobierno están al servicio de los gobernados, es normal que existan instancias que permitan, pero sobre todo auspicien, el ejercicio de los derechos ciudadanos.

\section{Participación. Tipos y modalidades}

En el caso mexicano la monopolización del poder gubernamental por parte del Partido Revolucionario Institucional (PRI) - la cual hasta después de medio siglo de existencia empezó a resquebrajarse en algunos puntos del país debido al reconocimiento del triunfo electoral de los partidos opositores- favoreció el hecho de que el partido fuera básicamente la única instancia ante la cual la mayor parte de los mexicanos podían y debían acudir para canalizar sus demandas frente al gobierno. El partido, a través de su estructura sectorial campesina (por ejemplo la Confederación Nacional Campesina), popular (la Confederación Nacional de Organizaciones Populares, ${ }^{4}$ entre otras) y obrera (Confederación de Trabajadores de México, por citar la más importante), ha operado como vehículo de enlace entre las demandas populares y el Estado. Lo que, a su vez, en cada contienda electoral se traducía en votos a favor del PRI. No en balde, los dirigentes de los tres sectores del partido podían anunciar antes de cada elección la cantidad de votos que sus afiliados arrojarían para los candidatos del partido de Estado. Lo cual, en muchos sentidos, permitía sacar a luz los mecanismos de coacción del voto y de fraude electoral a los que habría que echar mano, en orden de garantizar el triunfo de los candidatos priístas.

Para el caso mexicano existe una amplia literatura que da cuenta de los usos político-electorales de recursos tales como el clientelismo y el corporativismo. El primer concepto, de acuerdo con Mastropaolo (1981:273), se refiere al ofrecimiento que los políticos de profesión hacen, a cambio de legitimación y sostén, de los recursos públicos de los que pueden disponer. Frente a la inexistencia de mecanismos de- 
mocráticos de participación ciudadana y ante la ausencia de posibilidades económicas para acceder a la satisfacción de sus necesidades, los excluidos, como apunta Duhau (1999:10),

resultan inducidos a extender sus prácticas de intercambio articulándolas a los representantes de las instituciones estatales a través de uno o más intermediarios, es decir, a desarrollar prácticas clientelares, porque ésta resulta ser muchas veces si no la única, al menos una vía fundamental, de acceso a bienes y servicios de cuyo consumo están excluidos. Como contrapartida, quienes tienen a su disposición los recursos de autoridad pertinentes (gobernantes y funcionarios) encuentran con el intercambio clientelar con estos sectores sociales, un modo de utilización de sus recursos de autoridad que les proporciona una vía pragmática de definición de "prioridades" (organización del orden de prelación de demandas), un instrumento de control político de la población excluida y de proselitismo.

El corporativismo — que puede coexistir con prácticas de carácter clientelar - tiene que ver con la cooptación de la voluntad ciudadana a través de organismos colectivos de naturaleza sectorial o territorial que, con todo y asumirse como representantes de los intereses de sus agremiados, se encuentran supeditados a instancias de poder como pueden ser los partidos políticos y/o los gobernantes y, en consecuencia, condicionados a los intereses de estos últimos.

La alternancia política y la relativa pérdida del papel de intermediación del PRI —ante la política neoliberal puesta en marcha por los tres últimos gobiernos federales de extracción priísta (1982-2000) que significó un retroceso general en los niveles de ingreso y bienestar de los sectores populares - debilitó, mas no eliminó, el sistema de gobernabilidad autoritaria, sustentada en la participación manipulada de carácter clientelar y corporativo.

Es decir, que factores como los ya aludidos pueden dar cuenta de cierta transición de un modelo de gobernabilidad autoritaria a uno de gobernabilidad democrática (Duhau 1999; Ziccardi 1998; Ramírez 1998). Lo cual no desconoce que en muchos sentidos los recursos federales (incluso descentralizados, por no haber pasado a una etapa de devolución, afirma Victoria Rodríguez), como los destinados a combatir la pobreza, tales como el Programa de Educación, Salud y Alimentación, 
Progresa, (administración Zedillo) y el Programa de Apoyos Directos al Campo, Procampo, (el cual continuó con la administración de Fox) siguieron manejándose bajo criterios político-electorales, ${ }^{5}$ como sucedió en el sexenio de Carlos Salinas de Gortari (1988-1994) con respecto al Programa Nacional de Solidaridad (Acedo 1995; Ceja 1997; Cornelius, Craig y Fox 1994; Dresser 1991, 1992, 1996; Cortez et al. 1995; Laurell 1992; Méndez 1992; Moguel 1993, 1994 y, entre otros, Peniche 1992).

Se trataría pues de distinguir entre una participación mediatizada y tutelada por el (los) partido (s) y/o el Estado, que lejos de contribuir al pleno ejercicio de los derechos ciudadanos o de una ciudadanía activa, se orienta a la reproducción de sujetos subalternos, y, de diferenciarla de otra manera de participación institucionalizada o no, autónoma de los partidos políticos y del Estado, y fundamentada sobre todo en la conciencia de derechos y obligaciones. Sin embargo, resultaría dudoso afirmar que existe la participación como atributo de ciudadanía cuando no se forma parte de algo en calidad de actor (del derecho de participar en la toma de decisiones y de disfrutar la riqueza que se genera colectivamente), cuando los individuos son excluidos, convirtiéndose, en todo caso, en instancias dóciles de manipulación. Como en efecto sucede cuando desde el poder se cultivan prácticas populistas, estatistas, clientelares o, en general, antidemocráticas.

Para Jordi Borja, la participación es

el encuentro entre las instituciones representativas, partidos y Administración, por una parte, y los movimientos y organizaciones sociales, que existen autónomamente de los partidos políticos y de los mecanismos participativos (1996:118-119).

Como también lo es el

conjunto de instrumentos y procedimientos que las instituciones democráticas ponen a disposición de los grupos sociales más desfavorecidos para facilitar su intervención en la vida política y para estimular su desarrollo colectivo (Ibid.:141).

Sin embargo, es necesario distinguir, por un lado, entre instrumentos y procedimientos o instancias participativas (canales y medios), y por el otro, las modalidades bajo la que ésta se manifiesta (los modos), algunas de las cuales podrán resultar excluyentes entre sí. En la 
literatura sobre el tema es común encontrar la ausencia de diferenciación entre modos y medios de participación. De igual manera cabe reconocer que, sobre el concepto de participación, existen definiciones tanto de naturaleza genérica, como adjetivadas (ciudadana, social, comunitaria, política, etc.). Una definición general (es decir, a secas) del concepto de participación que resulta útil es la que aporta Lucía Álvarez (1997:27) cuando nos dice que ésta

consiste en primera instancia, en una actividad orientada hacia un fin; un fin que necesariamente se corresponde con encontrar respuesta o dar solución a una necesidad; lo cual dota a esta actividad de un elemento teleológico. Y la solución a una necesidad supone por lo general la modificación de las condiciones en que se plantea tal necesidad, o se reemplaza por otras que permitan atenderla. De esta manera se puede decir que la participación contiene también un elemento transformador.

Álvarez (Ídem.) señala que la participación se refiere: a) a una actividad que realizan algunos miembros de la sociedad en relación con el Estado o las condiciones que éste sustenta; b) a una actividad que puede realizarse de manera individual o colectiva, pero que persigue siempre fines colectivos; c) a una serie de acciones que se llevan a cabo dentro de o con respecto al ámbito público; y d) que se trata de una actividad con repercusiones sociales que acusa características como la intencionalidad, el grado de conciencia y la capacidad de transformación.

Existe también cierta distinción en cuanto a lo que puede considerarse como tipos o clases de participación (en ocasiones referidas por diversos autores como variantes, géneros o dimensiones). Ziccardi (1998:29) —quien a su vez se apoya en los trabajos de Nuria Cunill— reconoce cuatro tipos de participación: 1. La participación social, supone la asociación de individuos para el logro de determinados objetivos; 2. La participación comunitaria, se ubica en el campo de las actividades asistenciales propias del mundo de lo no estatal; 3. La participación ciudadana, se reserva a la relación que existe entre los individuos y el Estado, la cual pone en juego el carácter público de la actividad estatal; y 4. La participación política, que se relaciona con el ejercicio de derechos políticos básicos pilares de la democracia representativa como la selección de los gobernantes a través del sufragio. Aunque estas cuatro clases de participación no son excluyentes entre sí -y de hecho unas no pueden desarrollarse en ausencia de las otras- en tér- 
minos metodológicos resulta importante distinguirlas, ya que nos permiten vincularlas a las dimensiones constitutivas de la ciudadanía y, por lo tanto, a identificar de manera más precisa de qué tipo de cambios hablamos cuando estamos estudiando procesos de construcción de ciudadanía. Sin embargo, debido a que las fronteras entre un tipo de participación y otra no siempre resultan tajantes o excluyentes entre sí, es importante evitar la tentación teoricista de encasillar a los procesos mismos, lo que como advierte Álvarez (1997:37) supone

Llevar a cabo un acercamiento al fenómeno de participación despojado de conceptualizaciones previas que, más que buscar la expresión concreta del fenómeno, pretenden calificar al proceso en cuestión, o insertarlo en algún género de clasificación. Antes de buscar el carácter político, social o ciudadano de un procesos participativo, es preciso realizar una aproximación que nos permita observar los distintos niveles en que éste se manifiesta, identificar los elementos que lo delimitan, descubrir la conexión que establece con otros procesos y la forma en la que interviene en la transformación de la relación Estado-sociedad.

José Mejía (1996:38) distingue tres modalidades de participación: 1. La participación legal o formal se refiere a los derechos de los ciudadanos de elegir a sus gobernantes y a participar junto con ellos en la toma de decisiones. 2. La participación espontánea es la que obedece a iniciativas de la comunidad o de algún grupo de la misma en aras de buscar la resolución de un problema determinado. 3. La participación organiza$d a$ es aquella que es promovida por algún mecanismo o institución, como asociaciones de colonos, clubes de servicios, partidos políticos, comités de manzana, el gobierno municipal, etc., con el objeto de realizar obras y acciones. Acosta (1996:10) reconoce básicamente cuatro modalidades de participación: 1. La participación institucional, es aquella promovida y garantizada jurídicamente desde el gobierno. 2. La participación espontánea, que se da de manera coyuntural, dispersa y con débil articulación orgánica. 3. La participación manipulada, se promueve dentro o fuera del aparato gubernamental donde los intereses de los organizadores no necesariamente corresponden con los intereses de la ciudadanía movilizada. 4. La participación organizada, es la que los actores cuentan con formas autónomas de representación orgánica de sus intereses. En cambio, Ziccardi (1998:36) distingue cinco diferentes tipos de participación (estrictamente ciudadana): 1. La participación instituciona- 
lizada, que es la reglamentada para que la ciudadanía participe en los procesos decisorios del gobierno local; 2. La participación no institucionalizada, es aquella formal o informal pero no reglamentada; 3 . La participación autónoma, es en la que la ciudadanía participa a través de algún tipo de asociación no gubernamental que, aunque participe en instancias de gobierno, no depende ni es controlada por éste; 4. En la participación clientelística, la autoridad y los individuos o grupos se relacionan a través de un intercambio de favores o cosas; y 5. La participación incluyente o equitativa, es aquella en la que se promueve la participación de toda la ciudadanía, independientemente de la pertenencia o identidad partidaria, religiosa o de clase social. La clasificación de Acosta y de Ziccardi (ver cuadro 2) parecen más adecuadas ya que no obvian el juego de intereses que se dan entre los sujetos de la participación social y, sobre todo, los márgenes de autonomía o de manipulación en la que ésta podrá desarrollarse.

\section{Cuadro 2 \\ Modalidades de participación \\ (Según tres autores)}

\begin{tabular}{|l|l|}
\hline Autores & Modalidades de participación \\
\hline José Mejía & 1. Legal o formal \\
& 2. Espontánea \\
José Acosta & 3. Organizada \\
& 1. Institucional \\
& 2. Espontánea \\
& 3. Manipulada \\
Alicia Ziccardi & 4. Organizada \\
& 1. Institucionalizada \\
& 2. No institucionalizada \\
& 3. Autónoma \\
& 4. Clientelística \\
& 5. Incluyente \\
\hline
\end{tabular}

Y aunque la alternancia política municipal no necesariamente significa que quienes lleguen al poder instauren canales participativos y, por lo tanto, que la gente construya sus opciones - por lo menos 
cotidiana y sostenidamente gracias al papel del gobierno por fomentarla-, lo cierto es que es precisamente en los municipios en que ésta se ha dado donde usualmente han surgido nuevas experiencias de participación ciudadana. Así se ha observado en algunos municipios brasileños, donde ha gobernado el Partido del Trabajo; salvadoreños, donde lo ha hecho el Frente Farabundo Martí para la Liberación Nacional; uruguayos, donde gobierna el Frente Amplio; o mexicanos, en ayuntamientos presididos por alcaldes afiliados al Partido de la Revolución Democrática (PRD) o al Partido Acción Nacional (PAN) como de otros partidos opositores. Aunque un problema inherente a ello es la sucesión y el relevo de las autoridades municipales, ya que no siempre las que continúan -incluso siendo del mismo partido- tienen interés para proseguir con el trabajo realizado por su predecesor. Ante ello los procesos podrán quedar truncados, sobre todo al tratarse de experiencias aún no consolidadas.

No siempre la trayectoria política partidaria de algunos alcaldes (o jefes de gobierno) que se han caracterizado por impulsar instancias y procesos de participación ciudadana se desarrolló dentro de los partidos opositores. En algunos casos, como el mexicano, éstos incluso en cierto momento fueron miembros del PRI, partido con el que eventualmente rompieron para dar nacimiento o integrarse a otras organizaciones partidarias. Es la situación, menciono dos, de Cuauhtémoc Cárdenas Solórzano, quien, como titular del gobierno de la ciudad de México contribuyó a impulsar la reforma política y, dentro de ésta la Ley de Participación Ciudadana ${ }^{6}$; y la de Andrés Manuel López Obrador, actual jefe de gobierno de la ciudad de México.

Si bien la alternancia puede dar pie a procesos de participación ciudadana, lo cierto es que la primera no se presenta cuando las opciones partidarias son inexistentes. Como lo ha señalado Verduga (1996:85)

El desarrollo de un municipio democrático demanda la convergencia de una constelación de actores y mecanismos institucionales. En primer término, supone la existencia de partidos políticos $y$, por lo tanto, de opciones distintas para los cargos comunales de elección popular.

En ocasiones las opciones partidarias se han construido a partir de movimientos sociales de naturaleza local que, durante sus procesos de

Proximidad y participación ciudadana 
lucha, terminan vinculándose a partidos políticos regionales o nacionales. Lo que no significa - como he insistido- que su eventual arribo al gobierno local conduzca al despliegue de prácticas democráticas y a la ampliación de los márgenes de la participación ciudadana.

Si partimos de la premisa de que la descentralización política municipal deberá expresarse a través procesos de democratización, constitución de gobiernos representativos e instrumentación de formas de democracia directa o de participación ciudadana (sobre todo en sus modalidades institucional, espontánea y organizada) es necesario pensar en los mecanismos que la sustenten. Para que la participación ciudadana sea efectiva, se requieren, de acuerdo con Jordi Borja (1996:125), por lo menos cuatro condiciones o características:

- Que el gobierno local facilite el acceso a la información; esto contribuye a crear condiciones que coadyuven a la comunicación, al diálogo y a la interpelación de las partes.

- La división territorial de la ciudad de tal forma que exista una correspondencia entre el territorio específico habitado por la gente (calle, barrio, zona, sector, etc.) y su posibilidad de incidir en él.

- La organización político-administrativa que permita la comunicación y coordinación eficaz entre los representantes territoriales y el gobierno municipal; y

- El otorgamiento de competencias, funciones y recursos a los organismos sociales de carácter territorial y sectorial.

Es importante tomar en cuenta que sin la voluntad política de las autoridades locales resulta prácticamente imposible crear condiciones que permitan que la participación ciudadana se convierta en una forma de vida cotidiana que regule la relación entre ciudadanos y gobernantes. El relevo de los partidos políticos en la conducción de los ayuntamientos - como expresión de las opciones que desde la democracia representativa construyen a través de su voto los ciudadanos- y la posible búsqueda de su legitimación al guardar distancia de las prácticas mal vistas o indeseables de la administración saliente, ciertamente pueden permitir que las nuevas autoridades se conduzcan de forma más transparente o menos autoritaria. Aunque en ocasiones más bien se pueda tratar de gobernantes cuyo interés fundamental sea el de 
obtener beneficios personales - y de grupo-, por lo que abrir el campo de decisiones y de participación social, simplemente no tiene sentido: resulta ajeno a esa lógica del poder.

En la medida que el gobierno local no facilita el acceso y difusión de la información, crea sus propias condiciones para actuar con márgenes de discrecionalidad. El ciudadano común y corriente no tiene idea ni del plan de gobierno, ni de las instancias que dentro del propio ayuntamiento han sido creadas para su servicio o de las leyes o reglamentos que deberán normar la vida comunitaria. De igual manera, desconoce las fuentes y montos de los recursos financieros con los que cuenta el gobierno, sus partidas, criterios para su empleo, ni mucho menos conoce las maneras de como influir en todo ello. La información es clave como punto de partida para el ejercicio del derecho de influir en la toma de decisiones. De lo contrario se reproduce la cultura política clientelar, donde los actos de beneficio social (cuando los hay) de los gobernantes son un favor que eventualmente tendrá que pagarse y no una obligación gubernamental.

Ciertamente la participación no tiene razón de ser cuando la posibilidad de incidencia es nula, cuando no se sabe ni cómo, ni para qué involucrarse. Por ello, un indicador de la voluntad democrática de un gobierno es la importancia que otorga a la socialización de la información como vía para la construcción de canales de comunicación e incidencia ciudadana. Los canales pueden ser múltiples.

Tradicionalmente los ayuntamientos hacen uso de instrumentos de difusión, tales como boletines de prensa (si es que existen emisoras locales de radio y/o televisión o medios impresos como diarios o semanarios), gacetas (boletín oficial), periódicos murales, altavoz móviles o fijos (para informar de actividades de distinta naturaleza), o informes de gobierno (de circulación restringida). En cualquiera de éstos, el objetivo es básicamente el informar sobre cuestiones muy puntuales y no tanto el de establecer comunicación, diálogo o interpelación. Si bien es cierto que el tamaño de la población del municipio en buena medida influye para que determinados medios de difusión (prensa, televisión, radio) existan o no en el lugar, su inexistencia no constituye impedimento alguno para encontrar instancias o espacios alternativos de difusión y comunicación, tales como la reproducción y distribución escrita de información de interés municipal o la simple 
realización de reuniones entre los habitantes, sus organismos y los miembros del ayuntamiento.

La división territorial o zonificación del municipio y, a partir de ella, la constitución y reconocimiento legal de las instancias de representación ciudadana y la creación de canales de comunicación entre los ciudadanos - a través de sus representantes-y la burocracia van de la mano. No tiene sentido llevar a cabo zonificaciones cuando los organismos de representación son inexistentes (o sólo existen formalmente) o cuando no hay una relación de comunicación permanente entre las organizaciones territoriales (bases y representantes) y las autoridades locales.

\section{Instrumentos de participación ciudadana}

¿Qué experiencias de participación ciudadana se han dado en los municipios en los que ha existido la iniciativa de la población local y la voluntad de sus gobernantes para que ésta se lleve a cabo? ¿Cuáles han sido los instrumentos de participación creados para tal fin?

Diversos autores (Lombera 1996; Acosta 1996; Alonso y Ramírez 1997) han señalado cómo las experiencias recientes, por un lado, permiten constatar la existencia de novedosas prácticas en el campo de la democracia representativa y directa y, por el otro, la pervivencia de culturas políticas antidemocráticas. Entre estos autores, Rocío Lombera (1996:20-21) identifica como prácticas novedosas: 1. La celebración de elecciones legítimas y limpias donde no existe duda en cuanto a la veracidad de sus resultados; 2 . La institucionalización de la participación aceptada y fomentada por el gobierno local, protegida por leyes instituidas para tal fin y exenta de fines partidistas y propósitos clientelares; 3 . El desarrollo de la planeación participativa que permita la generación de procesos de reflexión colectiva entre población y autoridades, en una perspectiva de comprensión de la realidad global del municipio y su articulación regional y nacional, así como de visión y proyección de procesos de mediano y largo plazo, más que de atender o responder a demandas inmediatas y particulares; 4. La creación de una legislación amplia e incluyente formulada por iniciativa social para que la observancia y ejercicio de la misma sea indiscutible para todos; 5 . El protagonismo de la sociedad civil y ciudadanía activa, desarrollando el ejercicio pleno de todos los derechos por todos, fortaleciendo la construcción y consolidación de identidades sociales e incrementando la capacidad de 
formulación de propuestas, de toma de decisiones y de manejo y vigilancia de los asuntos públicos; 6. La puesta en marcha de mecanismos de control y vigilancia social de los recursos e instituciones públicas; 7. El desarrollo de la autonomía política y social local sustentada en procesos de autogestión, autodeterminación y autogobierno acompañados de una descentralización económica, política y administrativa que los fortalezca; 8. El logro de un desarrollo pleno e incluyente entendido como el mejoramiento real de las condiciones integrales de vida de todos los habitantes; 9. La formulación desde la sociedad de políticas públicas justas; y 10. La construcción de un poder local democrático.

A lo que habría que agregar como consecuencia de todo lo anterior la promoción de una cultura política que fomente la tolerancia, la discusión, el consenso y el respeto a la diversidad cultural existente tanto dentro, como fuera del propio municipio.

Aunque más adelante daré cuenta de algunas experiencias innovadoras en materia de participación ciudadana para el caso de ciudades latinoamericanas, antes de ello, vale la pena detenerse para mostrar lo que Jordi Borja y Manuel Castells —en su trabajo Local y global. La gestión de las ciudades en la era de la información (1997)_, ilustran con respecto al Proyecto de Carta Municipal para el caso de la ciudad catalana de Barcelona, España. Esta Ley contempló los siguientes mecanismos participativos:

1. Comunicación e información orientada a hacer efectivo el derecho de los ciudadanos a recibir información sobre las actividades municipales. Lo anterior, a través de la instalación de radiodifusoras y estaciones de televisión municipales, a cuyo acceso tendrán derechos los habitantes.

2. Información pública individualizada con el fin de que los ciudadanos puedan ser informados de la actuación de la autoridad local y reconociéndoles su derecho de manifestarse a favor, en contra, y de realizar sugerencias al respecto.

3. Consulta ciudadana que reconoce el derecho de todo ciudadano a ser consultado.

4. Derechos de sugerencia, petición y queja los cuales a su vez deberán de ser difundidos por los medios de comunicación a disposición del ayuntamiento. 
5. Audiencia pública, la que, sobre su programa de actuación y revisión de los presupuestos municipales y las ordenanzas fiscales, deberá de realizar el ayuntamiento en forma anual.

6. Iniciativa ciudadana, como aportación de medios económicos, bienes, derechos o trabajo personal para la realización de actividades de interés municipal, para lo cual los distritos deberán de dotar anualmente una partida presupuestaria.

7. Iniciativa reglamentaria relativa a la capacidad para proponer la aprobación de reglamentos, a través de los consejos de distrito o sectoriales o por iniciativa de un grupo promotor que cuente con el respaldo del uno por ciento de los empadronados mayores de 16 años.

8. Gestión cívica de infraestructura y equipamientos, la cual se crea como una nueva forma de intervención de la ciudadanía en la gestión municipal.

9. Campañas ciudadanas y cooperación municipal, orientadas a la articulación de la cooperación ciudadana, por ejemplo, en torno a acciones que den respuesta a problemas sociales, que contribuyan a mejorar la calidad de vida urbana, así como de promoción social y cultural.

10. Organismos de consulta y participación, que da pie a la conformación de Consejos Consultivos Territoriales y de Consejos Sectoriales, a los cuales deberán de consultar los órganos municipales para que de manera conjunta se propongan soluciones a problemas planteados.

11. Derecho a la intimidad y privacidad de los ciudadanos, que deberá guardar el ayuntamiento mediante la regulación de la utilización de registros, padrones y otros instrumentos públicos.

12. Acceso de la ciudadanía a la administración y transparencia del procedimiento administrativo, a través de distintos instrumentos como la "ventanilla única" o el "Teléfono 900" para la realización de determinadas gestiones administrativas.

13. Carta de Derechos Medioambientales, orientada a la defensa de los derechos ciudadanos relativos a la calidad de vida de los mismos. 
14. Defensa de los usuarios y consumidores, a través del reconocimiento de la capacidad municipal para defender los intereses de los ciudadanos ante las grandes empresas públicas y privadas, suministradoras de servicios públicos. La Carta Municipal reconoce la defensa general del ciudadano en tanto que consumidor, asumiendo competencias de inspección y sanción en materia de precios, etiquetado, presentación, publicidad, etc., y promueve la colaboración de entidades u organismos de sector.

15. Consejos de Justicia Municipal, cuyo principal objetivo es supervisar el funcionamiento del tribunal y de los juzgados municipales.

16. Seguridad ciudadana, para lo cual se contempló la constitución del Consejo Municipal de Seguridad Ciudadana y Prevención de la Delincuencia, integrado por autoridades de gobierno y representantes de la ciudadanía.

17. Consejo Tributario, que cuenta con la facultad de elaborar propuestas de resoluciones de los recursos y reclamaciones presentadas por los ciudadanos contra actos de carácter tributario. Que si bien no tienen un carácter vinculante podrán ser considerados por la instancia tributaria gubernamental.

18. Plan estratégico, orientado, entre otros aspectos, a garantizar la transparencia y el debate público en la definición y priorización de los grandes proyectos urbanos.

19. Participación pública en el urbanismo municipal, a la cual los vecinos tienen derecho de acceder mediante diversos instrumentos de participación.

20. Servicios sociales, que, por medio de acciones puntuales del ayuntamiento, deberán llevarse a cabo para beneficio de las personas y grupos menos favorecidos.

21. Acciones hacia sectores de población que requieren de una especial atención social, orientadas a fomentar la interrelación e integración a la vida ciudadana de grupos especiales de población, tales como: minorías étnicas, extranjeros, inmigrados, refugiados, población de paso o nómada, núcleos de población bajo gran pobreza, tercera edad, drogadictos, discapacitados, etc. 


\section{Descentralización y participación ciudadana en Montevideo, San Salvador y Porto Alegre}

Hace pocas décadas, Uruguay, El Salvador y Brasil, al igual que diversos países latinoamericanos, vivían bajo regímenes militares o civiles autoritarios. Los derechos civiles y políticos quedaron suprimidos y no pocos opositores sufrieron el exilio, la represión o la muerte. El retorno de los gobiernos civiles y de los derechos políticos y, con ello, la apertura institucional del juego electoral para los partidos de izquierda o centro izquierda, ha permitido que estos últimos hayan empezado a conquistar - a partir de la década de los ochenta pero básicamente de los noventa del siglo XX- espacios dentro del gobierno, particularmente en los ámbitos local o regional. Algunos de estos gobiernos locales conducidos por partidos de centro-izquierda han impulsado procesos de descentralización y participación ciudadana. Con todo y las resistencias y bloqueos de distintos sectores de interés (legislativos federales, partidos políticos o élites tradicionales, el ejecutivo federal en turno, etc.), para que este tipo de procesos no se asienten, las primeras experiencias muestran la importancia que adquiere la figura del alcalde (y su equipo de trabajo) como un actor central en la promoción de relaciones más horizontales entre gobernantes y gobernados, como también el hecho de que la consolidación de los hábitos participativos requieren varios años; por lo que en la medida que los procesos participativos no se consoliden (lo que implica su apuntalamiento jurídico) serán altamente vulnerables a los desenlaces electorales y a la voluntad o no de los nuevos gobernantes locales de seguirlos impulsando. Los casos que a continuación se describen simplemente intentan ilustrar algunas experiencias exitosas de descentralización y participación ciudadana en América Latina. Obviamente no son las únicas; sin embargo, han resultado ejemplares al haber sido retomadas y readaptadas por otros municipios de menor o mayor tamaño.

\section{El caso de Montevideo, Uruguay}

Hasta 1984, Uruguay retornó a la "normalización" de su vida democrática. En marzo de ese año el gobierno liberó al general Líber Seregni (ex candidato por el Frente Amplio a la presidencia de la República en 1971) y a José Luis Massera (ex secretario general del Partido Comunista) y anunció la celebración de elecciones para noviembre del mis- 
mo año. Las elecciones las ganó Julio María Sanguinetti, del Partido Colorado (partido político tradicional y responsable de la instauración de la dictadura), en un contexto de competencia partidaria desigual: a Seregni se le prohibió participar en las elecciones, como también a Wilson Ferreira Aldunate - ex candidato presidencial en 1971 por el Partido Nacional (Blanco)-, quien al haber retornado al país en junio de 1984, después de un exilio, fue inmediatamente encarcelado. Sin embargo, en 1989, el Frente Amplio ganó Montevideo, donde ya había mostrado ser la primera fuerza electoral en los comicios nacionales de 1971, donde había obtenido 30\% de los votos (De Sierra 1982).

Uruguay está conformado por diecinueve divisiones político-administrativas denominadas departamentos. El departamento de Montevideo es, en cuanto a su extensión, el más pequeño con 543 kilómetros cuadrados, pero con respecto a su población el más grande, ya que en él radican cerca de $50 \%$ de uruguayos, es decir, casi millón y medio de habitantes. La ciudad de Montevideo es capital departamental y además capital del país. Su área metropolitana incluye superficies de dos departamentos vecinos. En ella se concentra el $85 \%$ de la actividad industrial y comercial del país. Los intendentes de los departamentos duran en el cargo cinco años.

El proceso de descentralización de la Intendencia Municipal de Montevideo inició en 1990, a partir de la puesta en marcha de la administración encabezada por Tabaré Vázquez. El territorio del Departamento fue dividido en 18 zonas - que comprende 64 barrios del área urbana, suburbana y rural- ${ }^{7}$ En cada zona se instalaron Centros Comunales Zonales (CCZ) como unidades político administrativas desconcentradas del gobierno central y como entidades territoriales para el impulso de la estrategia de descentralización y participación ciudadana.

La política descentralizadora —según apunta Rosario Revello (1999) - ${ }^{8}$ se ha llevado a cabo a través de tres planos: el administrativo, el político y el social. Sus correlatos orgánicos son el Centro Comunal Zonal (director y funcionarios), la Junta Local y el Concejo Vecinal respectivamente (ver esquema 1).

El plano administrativo se basa en el Centro Comunal Zonal que, en los hechos, se convierte en la oficina administrativa de la Junta Local. Los centros comunales, encabezados por un director adminis- 
trativo, son los responsables de los servicios municipales. Ejecutan la gestión comunal en cada una de las zonas en subordinación a la Junta Local y al intendente a través del Departamento de Descentralización. Dicho departamento forma parte de la estructura central de la intendencia municipal y fue constituido con el fin de facilitar el proceso de descentralización hacia las 18 zonas que comprende el Departamento de Montevideo.

La Junta Local, conformada por representantes de los partidos políticos, funciona como un órgano político local descentralizado y es responsable de la dirección de la gestión comunal dentro de la zona. La junta se integra por cinco ediles locales designados por el intendente; correspondiéndole tres ediles al partido en el gobierno municipal, y dos a los partidos opositores. De estos cinco, uno ocupa el cargo de secretario de la Junta Local, quien - por ser una persona allegada al intendente y el responsable de articular la relación con el Departamento de Descentralización de la Intendencia- se ha convertido en el nodo de la red que constituyen el CCZ (Veneziano 2000).

Por último, el plano social se manifiesta por medio de los Concejos Vecinales que son las instancias de representación barrial. Se trata de órganos consultivos y asesores; sus concejales son electos por los vecinos y duran en el cargo dos años. A los vecinos les corresponde jerarquizar las obras o servicios que deberán ejecutarse dentro de sus propias zonas. Debido a que la solución para muchas necesidades no dependen del todo de la intendencia municipal, los concejos vecinales han aprendido a canalizar parte de sus demandas e iniciativas hacia otras instancias gubernamentales. Dentro de la estructura de los tres planos o polos son los únicos que ocupan cargos como resultado de un proceso electoral (cuyo calendario no empata con los comicios departamentales).

\section{Esquema 1}

\section{Los tres planos de la descentralización en Montevideo}

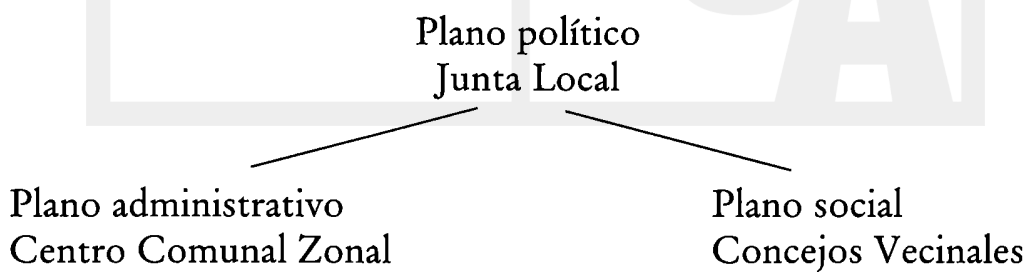


Alicia Veneziano (2000) ha identificado cuatro etapas en la evolución del sistema descentralizado de la Intendencia Municipal de Montevideo, las cuales han quedado marcadas por dos grandes variables; por un lado, el aprendizaje de la gestión de gobierno por parte del Frente Amplio y, por el otro, el bloqueo que, desde el sistema político, se ha realizado para frenar el proceso de descentralización. Estas etapas y sus características básicas son las siguientes:

1. La génesis del diseño descentralizador (1989-1990). Se desarrolla en un momento de negociaciones intrapartidarias entre las distintas fuerzas políticas que integran el Frente Amplio. El Partido Socialista, la Vertiente Artiguista y el Partido por el Gobierno del Pueblo, planteaban la creación de organismos zonales conformados por tres instancias: Juntas locales (con integración de los partidos políticos), asambleas deliberantes (constituidas por vecinos) y el delegado del intendente. En cambio el Partido Comunista y el Movimiento de Liberación Nacional-Tupamaros proponían el diseño de centros comunales sin la existencia de la figura de las juntas locales. A raíz del triunfo del Frente Amplio y de la posición personal del intendente electo al respecto se impone la segunda posición. Es decir, se busca reducir el papel de los partidos políticos como mediadores entre la intendencia y los ciudadanos ordinarios.

2. El primer año de gobierno opositor - señala Veneziano- se desarrolló entre el voluntarismo de la izquierda y el bloqueo por parte del sistema político. Se redactó el primer decreto de descentralización, se crearon las 18 zonificaciones que quedaron organizadas a través del delegado del intendente y las asambleas deliberantes. Pronto la administración se enfrentó a sus primeros dos obstáculos: a) la ausencia de una tradición de participación territorial, la cual en el pasado sólo se había desarrollado por medio de organizaciones sectoriales o a través de los partidos políticos; y b) un alto nivel de conflictividad entre el gobierno federal y el gobierno departamental, debido a que el proyecto de descentralización -que se llevaría a cabo al margen de los partidos políticos- atentaba contra las redes de naturaleza clientelar históricamente cultivadas entre los partidos y su base social.

3. El aprendizaje pluralista de la izquierda (1990-1993). A dos meses de haber transcurrido la nueva administración los partidos 
políticos tradicionales impugnaron constitucionalmente el decreto de descentralización del gobierno departamental. Mientras tanto el proceso descentralizador siguió su curso. Las negociaciones entre las fuerzas políticas conducen en junio de 1991 a la creación de la Comisión Mixta de Descentralización integrada por representantes de la intendencia de Montevideo, de la Junta Departamental de Montevideo (organismo legislativo del Departamento) y juristas. Las negociaciones culminaron con un nuevo decreto de descentralización (1993).

4. La implementación del sistema descentralizado que arrancó con la integración de las Juntas Locales (es decir, se retoma la idea inicial de algunas de las fuerzas del Frente Amplio que se manifestaban a favor del elemento partidario en el procesos de descentralización) y los Concejos Vecinales y se crea la figura del Secretario de la Junta Local que - como sucedía anteriormente con el delegado- es designado por el intendente. En 1995, tras el segundo triunfo consecutivo del Encuentro Progresista/Frente Amplio, la izquierda inició su segundo periodo de gobierno, ahora encabezado por Mariano Arana.

En mayo de 2000 , la coalición de izquierda volvió a ganar las elecciones municipales de Montevideo; Mariano Arana, fue reelecto con $57.8 \%$ de los votos para el periodo $2000-2005 .^{9}$

Durante este proceso de diez años, se han llevado a cabo tres elecciones de Concejos Vecinales (1993-1995-1998) y dos foros de discusión sobre el diseño y evaluación del proceso de descentralización y participación ciudadana en Montevideo (1992 y 1996). Con todo y los avances observados (a diez años de la izquierda en el gobierno de Montevideo y a poco más de quince de concluida la dictadura) cabe preguntarse acerca de las implicaciones que para el desarrollo de una sociedad civil autónoma conlleva la fuerte centralidad político-partidaria en el seno de los propios CCZ. El riesgo - como señala Veneziano- es que

las redes de articulación del Estado con la sociedad creadas por este tipo de descentralización, en un sistema político partidocéntrico, tienden -al contrario del objetivo buscado- a la partidización de la participación y de las nuevas instituciones (Veneziano 2000:24). 


\section{El caso de San Salvador, El Salvador}

El Salvador fue uno de los últimos países latinoamericanos en salir de la guerra. Fue hasta enero de 1992, cuando ésta concluyó formalmente al suscribirse los Acuerdos de Paz entre el gobierno - representado por Alfredo Cristiani del partido Alianza Republicana Nacionalista (ARENA) - y la guerrilla —aglutinada en el Frente Farabundo Martí para la Liberación Nacional (FMLN) - Con ello se cerró el último capítulo de violencia masiva en El Salvador -en doce años (1980-1992) murieron más de 75 mil personas en un país poblado con poco más de cinco millones de personas- ${ }^{10}$, y se abrió la posibilidad de que nuevos partidos políticos -fundamentalmente el FMLN- pudieran competir por los cargos de elección popular. El grado de desarrollo de la institucionalidad democrática, los procesos de descentralización y de alternancia política, y participación ciudadana en El Salvador, no pueden ser valorados en su verdadero significado, sin tomar en cuenta el terrorismo estatal que no hace mucho tiempo tenía canceladas las libertades y los derechos ciudadanos. Las dictaduras son la expresión máxima del centralismo y concentración del poder, por lo que difícilmente se puede hablar de procesos de descentralización en contextos represivos como el que caracterizó el pasado inmediato salvadoreño. Sin embargo, no se puede obviar el hecho de que, paralelamente a la cancelación de las libertades políticas, se gestaron - si bien no dentro de los marcos institucionales- procesos de participación (social, comunitaria, etc.) y nuevos actores (como aquellos propiciados a partir de las comunidades eclesiales de base o en los "territorios liberados" por el FMLN) que eventualmente, con el retorno de la democracia, pasarían a influir en la sociedad de la posguerra.

El Salvador, la menor de las repúblicas centroamericanas y la más densamente poblada, cuenta con una población superior a los seis millones de habitantes. El país se encuentra dividido en catorce departamentos y conformado por 262 municipios.

Varios factores influyeron para que en el transcurso de los años noventa se presentaran cambios significativos en materia de descentralización y fortalecimiento municipal. Shawn Bird (2000:11-12) los sintetiza en dos: 1) El fin de la guerra y los esfuerzos encaminados a la reconstrucción del país y 2) La adherencia a la doctrina neoliberal por parte del partido ARENA, entonces gobernante. En cuanto al primero, los Acuerdos de Paz, significaron el compromiso por impulsar reformas

\section{Proximidad y participación ciudadana}


que contribuyeran a eliminar las causas que habían propiciado el levantamiento armado, entre las que se encontraban la incapacidad de las instituciones locales. El fin de la guerra también propició la proliferación de organizaciones no gubernamentales, muchas de ellas orientadas a la búsqueda de procesos de constitución de ciudadanía y de desarrollo local y regional. Por consiguiente muchas de las agencias financieras internacionales consideraron el componente de la participación ciudadana como un requisito indispensable para el apoyo e impulso de proyectos de desarrollo local.

En cuanto al segundo, tanto el gobierno de Cristiani (1989-1994) como el de Armando Calderón Sol (1994-1999) adelgazaron el aparato del gobierno central y descentralizaron algunos recursos y funciones hacia los municipios. Durante estos periodos se creó el Fondo de Inversión Social para los municipios, se revivió la Asociación de Alcaldes Salvadoreños y se impulsó un programa general de descentralización. Algunas iniciativas, como la privatización de empresas estatales, fueron abiertamente promovidas por el gobierno central. Otras - como el aumento para los municipios del 1 al $6 \%$ del presupuesto nacional vía participaciones por iniciativa de los diputados opositores de la Asamblea Nacional-, tuvieron que ser implementadas ante la presión de actores diversos. ${ }^{11}$

Entre las reformas recientes impulsadas por algunos gobiernos locales se encuentran: 1) la constitución de Asociaciones de Desarrollo Comunales - que son organismos de representación vecinal- y de los Comités de Desarrollo Local —que aglutinan a representantes de organismos sectoriales y territoriales-. El Código Municipal permite la existencia de estos organismos. Formalmente son independientes del gobierno municipal y entre sus atribuciones están las de impulsar el desarrollo local y la participación ciudadana. La primera expresión de este comité apareció en 1994 y fue impulsada por la alcaldía de Nejapa; 2) La adopción de la planeación participativa y el diseño desde los Comités de Desarrollo Local del plan de desarrollo municipal, que si bien no es de carácter vinculatorio, si ejercita la participación (su aprendizaje, la conciencia de derechos y deberes, la integración, la vinculación con actores extralocales, etc.) y se convierte en una demanda colectiva que deberá de ser tomada en cuenta por el gobierno local; 3) El fortalecimiento de las finanzas municipales a través de la modernización de los sistemas de información y del cobro efectivo de impuestos y servicios munici- 
pales. La mayor parte de estas reformas empezaron a instrumentarse a partir de 1996 ó 1997 (Bird 2000).

El municipio de San Salvador, a su vez capital de la República, abarca 72 kilómetros cuadrados en los que residen medio millón de habitantes. El área metropolitana de San Salvador (también conocida como Gran San Salvador) comprende catorce municipios y en ella viven poco más de millón y medio de habitantes.

El fenómeno de la alternancia política municipal es relativamente reciente en la ciudad capital del país. En 1997, ARENA perdió las elecciones municipales; ello después de haber gobernado durante tres ayuntamientos consecutivos. El triunfo fue para Héctor Silva, candidato de una coalición constituida por cinco fuerzas políticas: el FMLN, la Convergencia Democrática, el Movimiento Unido, una fracción del Partido Demócrata Cristiano y una agrupación ciudadana no partidaria que después de la victoria electoral se bautizó como "Iniciativa Ciudadana". Las votaciones celebradas en marzo de 2000 las volvió a ganar Silva, quien fue reelecto para ocupar el cargo otros tres años. ${ }^{12}$ Lo que a continuación se expone da cuenta, a grandes rasgos, de la política de descentralización y participación ciudadana echada a andar durante la primera administración de Silva. ${ }^{13}$

Enríquez (2000) ha señalado cómo entre las principales decisiones asumidas por la primera administración de Silva, para fomentar la participación ciudadana se encontraron: a) abrir las sesiones de cabildo, b) dividir el municipio en siete zonas y c) formar mesas de concertación en cada una de las regiones (denominadas Mesas Zonales de Concertación) integradas, a su vez, por mesas de trabajo por sub-zonas (entre ocho y diez por zona). Las mesas zonales quedaron definidas como instancias de concertación y planificación del desarrollo zonal con las siguientes funciones: 1) diagnóstico de su zona, 2) priorización de problemas a enfrentar e identificación de sus soluciones, 3) elaboración de planes de desarrollo zonal, 4) gestión de recursos, 5) auditoría social del presupuesto municipal, 6) ordenamiento territorial, 7) ejecución de proyectos aprobados para la zona, 8) rendimiento de cuentas ante cada vecindario y sector de la zona y, entre otras, 9) corresponsabilizarse con la alcaldía en todas las acciones de interés para los vecindarios, la zona y la ciudad en su conjunto. Las primeras mesas zonales se instalaron durante los últimos meses del primer año de la administración de Silva. Cada 
mesa se constituyó con aproximadamente 150 delegados propietarios de naturaleza sectorial y territorial. Sin embargo, debido al reconocimiento que la existencia de organismos de carácter territorial no agotaban la representación de los intereses, pronto se arribó a la necesidad de conformar mesas o comisiones sectoriales, temáticas o especializadas para abordar problemas relativos a asuntos tales como salud, medio ambiente, género, cultura, etc.; lo que a su vez permitió la confluencia de otros actores individuales y colectivos. El gobierno municipal ha fomentado -aparte de la constitución de las instancias de participación ya mencionadas - otros espacios e instrumentos para facilitar la comunicación y la incidencia de los sansalvadoreños en los asuntos de interés público, entre ellos se encuentran la realización de forma abierta de las sesiones de cabildo, la consulta a través de plebiscito, el desarrollo de programas con teléfono abierto en los medios de difusión local y la instalación de buzones de sugerencias.

Como en Montevideo, en San Salvador también se creó una instancia dentro del gobierno municipal para coordinar las políticas de descentralización y de participación ciudadana; en este caso llamada Gerencia de Desarrollo Humano.

Por tratarse de una experiencia cuya vida es relativamente corta resulta difícil dar cuenta de los "saldos" de la participación social; precisamente debido a que su apuntalamiento o solidificación se da a través de procesos que requieren varios años, donde los sujetos de la participación social van modificando su propia cultura política; valga decir, creando conciencia de derechos y responsabilidades y afinando los instrumentos y la organización para (recreándolos) hacerlos valer.

La Fundación Nacional para el Desarrollo (FUNDE) ${ }^{14}$ realizó una primera evaluación de lo que considera como los principales escollos o dificultades a los que hasta hoy se ha enfrentado la política de descentralización echada a andar por el gobierno municipal, entre ellos, señala los siguientes: a) la dependencia de la cooperación internacional (financiamiento externo) por parte de la alcaldía para el impulso de la política; b) la falta de afianzamiento e institucionalización del marco legal; c) falta de difusión de la iniciativa participativa; d) la resistencia de muchos burócratas; e) la persistencia de patrones de cultura política paternalistas y de dependencia; f) la falta de información como elemento clave para la toma de decisiones; g) la rigidez institucional para responder pronta y adecuadamente a los compromisos adquiri- 
dos; y, entre otros, h) problemas en cuanto a la representación de la ciudadanía, sea de tipo territorial o sectorial (Enríquez 2000).

Ciertamente el gobierno municipal ha sido un actor clave en lo que hasta hoy se ha logrado. La reelección de Silva para un segundo periodo (2000-2003) permite afirmar que los primeros pasos tendentes a la descentralización estatal y a la participación ciudadana dados en el transcurso de la primera administración se consolidaron. Lo que no niega el desconocimiento de la existencia de algunas dificultades en el proceso de expansión de la participación social, entre ellas, la tentación entre algunos cuadros y dirigentes del FMLN por establecer mecanismos de sujeción entre las organizaciones sociales territoriales y sectoriales y el partido.

\section{El caso de Porto Alegre, Brasil}

Brasil vivió durante 21 años bajo gobiernos militares. En efecto, en abril de 1964, —con el beneplácito del gobierno de los Estados Unidos-, los militares dieron un golpe de Estado y tomaron el poder, el cual no entregaron hasta marzo de 1985; cuando José Sarney, candidato a la vicepresidencia por la opositora Alianza Democrática, tomó posesión como presidente interino. En abril de 1985, tras la muerte de Tancredo Neves, el presidente electo, Sarney asumió el cargo de manera definitiva. La oposición triunfó gracias a los resultados de una elección indirecta: fueron los miembros del colegio electoral (constituido por las asambleas legislativas de los estados) los que votaron. No fue sino hasta la siguiente elección - ganada por Fernando Collor de Mello- cuando a los ciudadanos se les restituyó el derecho de participar en elecciones presidenciales.

Porto Alegre, capital del estado Rio Grande do Sul, se encuentra habitada por más de dos millones de personas y ha sido un referente obligado cuando se habla de procesos de descentralización y participación ciudadana en América Latina.

Entre las razones que así lo explican se encuentran las siguientes:

1. Fue aquí donde, para el caso brasileño, se instrumentó por primera vez el presupuesto participativo (orcamento participativo). Éste se da a través de la división zonal del municipio, allí se realizan asambleas y por medio de algunos criterios se elabora un rol de obras y servicios que deberán de ejecutarse y ser incluidos en

Proximidad y participación ciudadana 
la ley presupuestaria municipal (Instituto Brasileiro de Administração Pública 1996). Consiste, pues, en depositarle a los ciudadanos el derecho a decidir el destino que deberá tener el presupuesto que, con respecto a la obra pública, maneja el gobierno local. Este mecanismo participativo fue echado a andar por el Partido del Trabajo (PT) en 1989, tras su triunfo electoral. Se trató de una de las primeras experiencias latinoamericanas en este renglón. A diez años de distancia más de cien municipios y tres estados (Rio de Janeiro, Pernambuco y Rio Grande do Sul) brasileños han reproducido el programa de presupuesto participativo, en buena medida tomando como referente a Porto Alegre (Wampler 2000).

2. El PT ha logrado conservar el municipio al ganar todas las elecciones locales posteriores (fue reelecto en 1992 y 1996), ello le ha permitido consolidar la estructura y los mecanismos de participación ciudadana. Tarso Genro encabezó la segunda administración petista, y Ponte la tercera. De hecho, en 1998, el partido logró ganar la gubernatura de Rio Grande do Sul, entidad donde se encuentra la ciudad portuaria de Porto Alegre.

Aparte de la disponibilidad de los gobernantes locales para el impulso de este tipo de iniciativas, hay que tomar en consideración que, en materia de distribución fiscal, Brasil es uno de los países menos centralistas en América Latina, gracias a que la nueva constitución nacional de 1988 otorgó una partida importante para los gobiernos estatales y municipales. Mientras que en $1988,71 \%$ de los ingresos fiscales pasaron a manos del gobierno federal, $25.5 \%$ a las entidades, y casi $3 \%$ a los municipios; en 1998 - diez años después- el orden fue el siguiente: $36 \%$ para el gobierno federal, $42 \%$ a las entidades federativas y un 21\% para los municipios (Nylen 2000). La descentralización de estos recursos ciertamente influye para que éstos estén más cercanos a la gente y que - por su monto- realmente resulten significativos para la solución de ciertas demandas de naturaleza local.

Antes del nacimiento del PT (1980), Porto Alegre - como muchas localidades brasileñas - experimentó movilizaciones populares en demanda de servicios urbanos, suelo y/o vivienda. Los militares se enfrentan a una oposición organizada y apoyada, entre otros, por sectores progresistas de la Iglesia católica, organizaciones gremiales o acti- 
vistas de izquierda. Uno de los organismos más importantes que surgieron durante los años setenta fue la Unión de Asociaciones de Porto Alegre (União das Associações de Moradores de Porto Alegre), cuyos líderes eventualmente fueron ligándose con el PT. Con un $34 \%$ de la votación y bajo las siglas del PT, Olivio Dutra, uno de los sindicalistas que contribuyó a la fundación del PT, logró ganar las elecciones municipales de 1988 (Wampler 2000:15).

La administración de Dutra tuvo que encarar fuertes problemas durante los primeros dos años de su gestión, entre ellos a) una huelga de empleados municipales provocada por la incapacidad del gobierno de sostener sus sueldos (un día antes de concluir la administración saliente ésta elevó los salarios de los empleados de tal manera que cerca de $90 \%$ del presupuesto municipal tenía que destinarse a ese rubro). El conflicto se resolvió tras el acuerdo entre las partes de ligar los sueldos con los ingresos municipales. Sin embargo, durante el primer año de gobierno hubo muy poca obra pública, ya que Dutra se resistió a encarar la disposición de la política salarial de último momento de la administración anterior; b) las distintas posturas al interior del PT entre administradores gubernamentales y responsables del movimiento popular y sindical en cuanto a que si el partido debería de gobernar sólo para los trabajadores o para toda la ciudad, lo que condujo a la decisión de gobernar para la ciudad, pero invirtiendo el orden de prioridades; c) un intento frustrado de desprivatizar el transporte público; d) problemas en cuanto al desconocimiento de la administración pública de parte del equipo de gobierno, así como de la insuficiencia de cuadros técnicos y profesionales dentro del mismo; y, entre otros, pero que más nos interesa; e) el de poner en marcha el andamiaje de la participación ciudadana. Se intentó, sin éxito, echar a andar consejos populares sin tomar en cuenta las formas de organización ciudadana que a manera de consejos comunitarios o asociaciones de pobladores ya existían en el municipio; a las cuales finalmente se tuvo que tomar en cuenta en orden de arrancar con el proceso de participación que promovía la alcaldía (Harnecker 1993).

De una primera zonificación realizada por la administración que consistió en dividir al municipio en cinco regiones, se pasó a otra que -recogiendo la opinión de los dirigentes comunitarios- contempló la división en 16 microregiones. En cada una de ellas fueron electos dos representantes, con éstas 32 personas se conformó el consejo de

Proximidad y participación ciudadana 
representantes, posteriormente convertido en Consejo Municipal de Plan de Gobierno. A su vez, en sesiones plenarias realizadas en cada microregión, se procedió a la elección de delegados (en proporción de uno por cada diez asistentes a las plenarias) y de aquí se pasó a la detección de las necesidades y a la priorización de las obras a realizar. Las primeras obras que se llevaron a cabo se encaminaron a tareas de saneamiento, como instalación de drenaje y agua potable. Conforme se cubrieron estas necesidades se pasó a la atención de otras, como resolver la titulación o regularización de la tenencia de la tierra, la instalación de clínicas, escuelas, etc. La confluencia de representantes de múltiples barrios de Porto Alegre para discutir y aprobar el orden en que se llevarían a cabo las obras, ha permitido que éstos tengan una visión global de la problemática urbana. Lo cual ha propiciado una mayor integración de la sociedad local y despertado actitudes de solidaridad frente a los barrios que padecen necesidades más urgentes a resolver. Como lo señaló Olivio Dutra, primer alcalde petista de Porto Alegre,

salir de lo local y específico, para alcanzar lo global es muy importante. Creo que en las discusiones del presupuesto participativo, por ejemplo, el hacer públicos los ingresos de la ciudad para que el presupuesto de la ciudad sea debatido por todos, ayuda a que las asociaciones comunitarias, piensen más allá de sus intereses locales, vean la ciudad en su conjunto, y eso facilita que los sectores más necesitados, más sufridos y explotados, se integren a un movimiento articulado para discutir en mejores condiciones la renta de la ciudad, rompiendo así con su corporativismo (Harnecker 1993:32$33) .{ }^{15}$

En el transcurso del tiempo - y en la medida que la planeación participativa ha mostrado sus frutos- ha habido una tendencia creciente hacia el involucramiento de la sociedad: de contarse con menos de 200 representantes en 1990, se pasó a más de 15000 hacia finales de los años noventa (Wampler 2000). ${ }^{16}$

\section{Conclusiones}

El reconocimiento gubernamental de las organizaciones territoriales (y sectoriales) como interlocutoras de la sociedad civil implica el respeto de su autonomía y el dotarlos de los recursos necesarios (infraestructura, funciones propias y de carácter vinculatorio, recursos fi- 
nancieros, espacios para su expresión, asesoría etc.) para su pleno ejercicio. En la medida que este apoyo sea de carácter institucional, que sea un acuerdo del cabildo y que como tal se encuentre normado, dicho apoyo no tiene por qué significar dependencia política hacia la autoridad; por tratarse precisamente de un derecho reconocido y no de un "favor discrecional". Como advierte Jaime González (1999: 274) "en nuestros países la sociedad civil debe ser promovida y fortalecida desde el Estado, tanto a nivel central como regional y local (...) De una administración funcionario céntrica debe pasarse a otra ciudadanocéntrica, usuariocéntrica; esto implica un cambio cultural y, por lo tanto, educación, incentivos y tiempo".

A pesar del fenómeno de la alternancia política nada nos garantiza que la relación viciada entre gobernantes y súbditos se deje de dar. Tampoco nos lo podrá garantizar la reelección de los gobernantes o la ampliación de sus periodos de gobierno. Se requiere sobre todo un cambio de actitud de ambas partes. Su mejor manifestación se da mediante la descentralización del poder y la apertura y fomento de espacios para la participación ciudadana.

No son pocos los funcionarios que consideran que su elección les permite tomar cualquier tipo de decisión a nombre de los electores aunque lo usual es que éstas se tomen a espaldas de los mismos. El problema, en mucho, tiene que ver en cómo combinar democracia representativa con nuevas formas de democracia directa. No podemos sólo cuidar el primer aspecto. No se trata sólo de atender el problema de cómo las élites compiten entre sí y de cómo hacerle para que estas competencias resulten más equitativas entre las partes. Como lo ha señalado el subcomandante Marcos,

la política es hoy un asunto de élites, democratizarla no significa ampliar esas élites o suplirlas por otras, sino "liberar" la política del secuestro en que la mantienen los políticos y llevarla hacia abajo, hacia quienes deben mandar y en quienes reside la soberanía: los ciudadanos. ${ }^{17}$

Sin lugar a dudas, la participación ciudadana es el mejor antídoto para romper con la reproducción de prácticas políticas elitistas (de la apropiación privada de lo público), aunque ciertamente se trata de procesos que requieren apuntalarse sobre bases de cultura política democrática. Ningún gobierno -o partido político- por tan bien intenciona- 
do que fuese puede lograr cambios de profundidad sin la colaboración de una ciudadanía activa.

\section{Bibliografía}

Acedo Angulo, Blanca (coord.) (1995). Solidaridad en conflicto. El funcionamiento del Pronasol en los municipios gobernados por la oposición. México: Nuevo Horizonte Editores.

Acosta Arévalo, José Octavio (1996). "Las relaciones políticas de los gobiernos locales". Participación ciudadana. México: Centro de Servicios Municipales "Heriberto Jara" A. C. y Friedrich Ebert Stiftung, noviembre (serie Antologías), pp. 5-28.

Aguirre, Rosario (1995). "Ciudadanía, democracia y mujeres. La contribución de las mujeres a la política democrática en América Latina". La Piragua. Revista Latinoamericana de Educación y Política. Santiago, Chile: Consejo de Educación de Adultos de América Latina (CEAAL), núm. 10, primer semestre, pp. 11-20.

Alonso, Jorge (1995). "Construir la democracia desde abajo". Nueva Antropología. Revista de Ciencias Sociales. México: UAM/G. V. Editores, núm. 48 , julio, pp. 67-82.

y Juan Manuel Ramírez S. (1997). “Introducción”. Jorge Alonso y Juan Manuel Ramírez Sáiz (coords.). La democracia de los de abajo en México. México: La Jornada Ediciones, Consejo Electoral del Estado de Jalisco y Centro de Investigaciones Interdisciplinarias en Humanidades de la UNAM, pp. 15-27.

Álvarez Enríquez, Lucía (1997). “Introducción general”. Lucía Álvarez Enríquez (coord.). Participación y democracia en la ciudad de México. México: La Jornada Ediciones y Centro de Investigaciones Interdisciplinarias en Ciencias y Humanidades de la UNAM, pp. 15-39.

Arocena, José. (1995). El desarrollo local: un desafío contemporáneo. Caracas: Centro Latinoamericano de Economía Humana, Universidad Católica del Uruguay y Editorial Nueva Sociedad.

Bird, Shawn (2000). "Institutionalizing Local Democracy. Decentralization, Municipalismo, and Citizen Participation in El Salvador". Mecanoescrito, ponencia presentada en el XXII Congreso de la Latin American Studies Association, Miami, 16-18 de marzo 2000. 
Borja, Jordi (1996). "Descentralización y participación ciudadana” Participación ciudadana. México: Centro de Servicios Municipales "Heriberto Jara," A. C. y Friedrich Ebert Stiftung, noviembre (serie Antologías), pp. 117-153.

\section{ciudades en la era de la información. Taurus y United Nations for Human Settlements (Habitat). \\ Castro Silva, Claudete de y Tania Margarete Keinert (1996). “Globali- zación, Estado nacional e instancias locales de poder en América Lati- na”. Nueva Sociedad, Caracas: Nueva Sociedad, núm. 142, marzo-abril, pp. 96-107.}

Ceja Martínez, Jorge (1997). Andar baciendo politica. La democracia desde abajo y el vinculo local-global en el caso del Pronasol. Guadalajara: El Colegio de Jalisco y Universidad de Guadalajara (Colección Grados).

Cornelius, Wayne, Ann L. Craig y Jonathan Fox, (eds.). (1994). Transforming State-Society Relations in Mexico. The National Solidarity Strategy. San Diego: Center for U. S.- Mexican Studies- University of California.

Cortez, Carlos, Gisela Landázuri y Patricia Moreno (1995). "El Pronasol: ¿Un modelo alternativo para el combate a la pobreza? Luis Alberto de la Garza y Alberto Nieto (coord. modulares tomo I) Distribución del ingreso y políticas sociales. México: Equipo Pueblo, Enlace, Foro de Apoyo Mutuo y Juan Pablos Editor, pp. 92-105.

Duhau, Emilio (1999). "Dilemas de los gobiernos locales de alternancia en México". Ciudades, México: Red Nacional de Investigación Urbana, núm. 41, enero-marzo, pp. 9-15.

Dresser, Denise (1991). Neopopulist Solutions to Neoliberal Problems. Mexico's National Solidarity Program. San Diego: University of California-Center for U.S.-Mexican Studies.

(1992). "Pronasol: los dilemas de la gobernabilidad". El Cotidiano. México: Universidad Autónoma Metropolitana-Azcapotzalco, núm. 49, julio-agosto, pp. 49-57.

(1996). "Aturdida y confusa: la política social en México desde el levantamiento de Chiapas”. El Cotidiano. México: Universi- 
dad Autónoma Metropolitana-Azcapotzalco, núm. 76, mayo-junio, pp. 93-104.

Enríquez Villacorta, Alberto (2000). "La participación ciudadana en el desarrollo del municipio de San Salvador, El Salvador". Mecanoescrito, ponencia presentada en el XXII Congreso de la Latin American Studies Association, Miami, 16-18 de marzo 2000.

González Graf, Jaime (1999). "La participación ciudadana como expresión de la democracia”. Carlos Contreras (coord.). América Latina en el siglo XXI. De la esperanza a la equidad. México: Fondo de Cultura Económica y Universidad de Guadalajara, pp. 253-277.

González Saravia, Dolores (1998). “Autonomía local y municipio”. Grupo Parlamentario del PRD Cámara de Diputados/LVII Legislatura Congreso de la Unión Autonomía local y reforma municipal, pp. 2732.

Guillen, Tonatiuh (1998). "Autonomía, libertad municipal y federalismo". Autonomía local y reforma municipal. Grupo Parlamentario del PRD Cámara de Diputados/LVII Legislatura Congreso de la Unión pp. 177-186.

Harnecker, Marta (1993). Alcaldía de Porto Alegre. Aprendiendo a gobernar. La Habana: Centro de Recuperación y Difusión de la Memoria Histórica del Movimiento Popular Latinoamericano (MEPLA) y Alcaldía de Durango, México (Col. Haciendo camino al andar, 2).

Hiernaux, Daniel (1995). "Desequilibrios estructurales y desigualdades regionales. Alternativas para el territorio mexicano". José Luis Calva (coord.). Desarrollo regional y urbano en México. Tomo I. México: Juan Pablos Editor, UNAM y Universidad de Guadalajara, pp. 25-41.

Instituto Brasileiro de Administracao Pública (IBAP) (1996). Institucionalização da participação popular nos municípios brasileiros. São Paulo: IBAP. (Cuadernos, 1).

Laurell, Asa Cristina (1994). "Pronasol, o la pobreza de los programas contra la pobreza”. Nueva Sociedad. Caracas: Nueva Sociedad, núm. 131, mayo-junio, pp. 156-170.

Lombera, Rocío (1996). "La participación social en el ejercicio de gobierno y en la construcción de poder local". Programa de Desarrollo y 
Gestión Municipal del COPEVI Democracia, desarrollo y autonomía municipales. Experiencias y propuestas, pp. 13-21.

Long, Norman. (1992). "From Paradigm Lost to Paradigm Regained? The Case for an Actor Oriented Sociology of Development". Norman Long y Ann Long (eds.). Battlefields of Knowledge. The Interlocking of Theory and Practice in Social Research and Development. Londres y Nueva York: Routledge, pp. 16-43.

Mastropaolo, Alfio (1981). "Clientelismo". Norberto Bobbio y Nicola Matteucci Diccionario de política. $2^{\mathrm{a}}$. ed. México: Siglo XXI, Editores, pp. 271-271.

Mejía Lira, José (1996). "La participación ciudadana en los municipios en la nueva relación Estado-sociedad". Participación ciudadana. México: Centro de Servicios Municipales "Heriberto Jara" A.C. y Friedrich Ebert Stiftung, noviembre (serie Antologías), pp. 29-47.

Méndez, Luis, Miguel Ángel Romero y Augusto Bolivar (1992). "Solidaridad se institucionaliza". El Cotidiano. México: Universidad Autónoma Metropolitana-Azcapotzalco, núm. 49, julio-agosto., pp. 60-71.

Moguel, Julio (1993). "No es tan nuestro el Pronasol”. Memoria. México: Centro de Estudios del Movimiento Obrero y Socialista, núm. 61, diciembre, pp. 5-7.

(1994). "El Pronasol en el horno chiapaneco". El Cotidiano. México: Universidad Autónoma Metropolitana-Azcapotzalco, núm. 61, marzo-abril.

Nylen, William R. (2000). "Testing the Empowerment Thesis: The Participatory Budget in Belo Horizonte and Betim, Brazil”. Mecanoescrito, ponencia presentada en el XXII Congreso de la Latin American Studies Association, Miami, 16-18 de marzo 2000.

Peniche, Antonio (1992). "El Pronasol: algunas notas y reflexiones generales”. El Cotidiano. México: Universidad Autónoma Metropolitana-Azcapotzalco, núm. 49, julio-agosto, pp. 20-23.

Ramírez Sáiz, Juan Manuel (1998). "Introducción”. Juan Manuel Ramírez Sáiz (coord.). ¿Cómo gobiernan Guadalajara? Demandas ciudadanas y respuestas de los ayuntamientos. México: Instituto de Investigaciones Sociales de la UNAM, CUCSH-Universidad de Guadalajara y Miguel Ángel Porrúa, pp. 13-32. 
Revello, Rosario (1999). "Comentarios a las ponencias de Jorge Ceja Martínez y Jaime Preciado Coronado y aporte sobre la experiencia de Montevideo". Congreso virtual iberoamericano "El municipio hacia el siglo XXI", http://www.rim.unam.mx/CONGVIR/MAT

Rodríguez, Marcos (1999). "A propósito de la transferencia del 6\% a las municipalidades" Alternativas para el Desarrollo. San Salvador: Fundación Nacional para el Desarrollo, núm. 60, septiembre-octubre, pp. 8-18.

Rodríguez, Victoria E. (1997). Decentralization in Mexico. From Reforma Municipal to Solidaridad to Nuevo Federalismo. Boulder: Westview Press.

Sierra, Gerónimo de (1982). "Consolidación y crisis del "capitalismo democrático" en Uruguay". Pablo González Casanova (coord.) América Latina: historia de medio siglo. Tomo 1: América del Sur. $3^{\mathrm{a}}$. ed. México: Siglo XXI Editores, pp. 431-457.

Touraine, Alain (1997). ¿Podremos vivir juntos? Iguales y diferentes. Buenos Aires: Fondo de Cultura Económica.

Veneziano Esperón, Alicia (2000). "La participación en la descentralización del gobierno municipal de Montevideo (1990-2000): evaluación de 10 años de gobierno de izquierda y reflexiones para América Latina”. Mecanoescrito, ponencia presentada en el XXII Congreso de la Latin American Studies Association, Miami, 16-18 de marzo 2000.

Verduga Vélez, César (1996). "Descentralización y poder local”. Participación ciudadana. México: Centro de Servicios Municipales "Heriberto Jara", A. C. y Friedrich Ebert Stiftung, noviembre (serie Antologías), pp. 81-87.

Wampler, Brian (2000). "Participatory Publics and the Execitive: Participatory Budgeting Programs in Recife and Porto Alegre". Mecanoescrito, ponencia presentada en el XXII Congreso de la Latin American Studies Association, Miami, 16-18 de marzo 2000.

Ziccardi, Alicia (1995). "La tarea de gobernar: las ciudades y la gobernabilidad". Alicia Ziccardi (coord.). La tarea de gobernar: gobiernos locales y demandas ciudadanas. México: Instituto de Investigaciones Sociales de la UNAM y Miguel Ángel Porrúa, pp. 13-37. 


\section{(1998). Gobernabilidad y participación ciudadana en la}

ciudad capital. México: Instituto de Investigaciones Sociales de la UNAM y Miguel Ángel Porrúa.

\section{NOTAS}

1. En entrevista realizada por Marta Harnecker (1993:34).

2. Aunque el presente trabajo no intenta abordar en lo específico el proceso descentralizador en México, cabe reconocer que sí ha habido ciertos cambios por tan pequeños que éstos puedan parecer- sin que ello signifique negar que el poder ejecutivo federal permanezca siendo altamente centralista, o que como ha apuntado Tonatiuh Guillen (1998:181) se está ante procesos de descentralización todavía centralizados.

3. De la distribución que se hace de los ingresos fiscales, la federación se queda con $80 \%, 17 \%$ pasa a los estados, y entre 3 y $5 \%$ se otorga a los municipios. Andrew Nickson - referido por Carlos Marichal - ha señalado a México como uno de los países más centralistas en América Latina: mientras que en el decenio de 1990 los gobiernos municipales mexicanos ejercieron en su conjunto apenas $3 \%$ del total del gasto público, en Brasil, los municipios controlaron el $18 \%$ y en Colombia, $24 \%$ del gasto total ejercido dentro sus respectivos países. La Jornada, enero 15, 1999:36.

4. Después UNE o Movimiento Territorial.

5. Esto es constantemente denunciado, particularmente en periodos de campañas electorales, por ser cuando el sistema clientelar entra a toda marcha. Con respecto a los usos clientelares del Progresa para favorecer al PRI véanse, por ejemplo, los resultados de un estudio realizado por la Comisión de Desarrollo Social de la Cámara de Diputados donde se evidencia una correlación casi perfecta entre el número de familias beneficiadas y los resultados electorales en los estados de Nayarit, Michoacán y Veracruz. Ignacio Rodríguez Reyna, "La perfecta armonía entre el Progresa y los votos del PRI. Casi asegurados casi 7 millones de sufragios" y Alejandro Almazán R., "El miedo de que se les acabe el Progresa lo resuelven votando por el PRI", en Milenio, Semanario publicado por Grupo Editorial Multimedios, México, núm. 123, enero 17, 2000. pp. 36-39 y 40-44 respectivamente.

6. La cual incluye figuras como el plebiscito, referéndum, iniciativa popular, establece la conformación de los comités vecinales y, entre otros, de consulta vecinal.

7. Hacia finales de la década de los noventa la zona 18 era la que contaba con el menor número de población, 34780 habitantes. En cambio las zonas 5 y 9, las más pobladas: la primera, con 130787 habitantes, la segunda, con 126717 (Veneziano 2000).

8. Asesora de la Intendencia Municipal de Montevideo.

9. El segundo lugar lo obtuvo el Partido Colorado (27.78\% de los votos) y el tercero fue para el Partido Nacional (11.58\%). La Jornada, mayo 16, 2000.

10. Estas cifras superan la cantidad de muertos que sufrieron los estadounidenses durante la guerra contra Vietnam. La población en Estados Unidos era entonces cercana a los 200 millones de habitantes. Esta simple comparación nos ilustra el grado de devastación que El Salvador sufrió durante los años de guerra, de tal 
manera que prácticamente no existe familia en el país que entre sus miembros no cuente con muertos o lisiados como resultado del conflicto.

11. La lucha por el aumento de las participaciones, desarrollada en 1997, involucró a todos los alcaldes salvadoreños; éstos, a través de su asociación nacional, presionaron para que la Asamblea Legislativa, aprobara el decreto respectivo. Sin embargo, la idea original partió de una propuesta elaborada por la Red para el Desarrollo Local integrada por seis instituciones de la sociedad civil (FLACSO, FUNDAMUNI, FUNDAUNGO, FUNDE, FUSAI Y SACDEL). Sin embargo, la distribución del $6 \%$ no es parejo para todos los municipios, ya que éste se distribuye de la siguiente forma: $25 \%$ en partes iguales entre los 262 municipios, $50 \%$ en forma inversamente proporcional a la cantidad de población de cada municipio (entre menos población, mayor el monto), otro $20 \%$ se distribuye de acuerdo al criterio de pobreza, y el $5 \%$ restante se distribuye en forma directamente proporcional a la extensión territorial de los municipios. En Rodríguez, Marcos (1999).

12. El FMLN fue el principal triunfador en las elecciones nacionales llevadas a cabo en marzo de 2000. En éstas el partido de la ex guerrilla ganó la capital, pero también otros 77 municipios (entre ellos casi todos los que constituyen la zona metropolitana); entre una elección y otra pasó a gobernar de 54 a 78 municipios. Ganó 8 de las 14 cabeceras provinciales y obtuvo 31 diputaciones (de las restantes, 29 fueron para ARENA y 24 para otros cuatro partidos). El gran perdedor fue ARENA, que, entre una elección y otra, pasó a gobernar de 170 a 124 comunas. Público marzo 14, 2000: 34.

13. Para ello, nos basamos centralmente en el trabajo de Enríquez (2000).

14. FUNDE es una ONG con sede en San Salvador, El Salvador. A partir de junio de 1999 asumió la tarea, junto con la Gerencia de Desarrollo Humano, de iniciar una primera evaluación de la política de descentralización y participación ciudadana impulsada por la alcaldía de San Salvador. Alberto Enríquez es el director del área de desarrollo local de FUNDE.

15. Se trata de una entrevista concedida a esta autora y que aparece en su trabajo ya aludido.

16. Esta cifra la retoma Wampler, basándose en el trabajo Orcamento participativo: reflexoes sobre a experiencia de Porto Alegre de Luciano Fendozzi. Porto Alegre, 1998.

17. Comunicado del EZLN, $1^{\circ}$ de julio de 1997. En: http://www.ezln.org/documentos/1997/19970701.es.htm 